\title{
GRUPO TERAPÊUTICO AD [ÁLCOOL E OUTRAS DROGAS] NO CAPS DURANTE O PERÍODO PANDÊMICO
}

\author{
Jacqueline Formigari \\ Carla Maysa Wenderlich Wessling \\ DOI: http://dx.doi.org/10.18616/intcov35
}

O Centro de Atenção Psicossocial (CAPS) é um local de referência para pessoas com transtornos mentais, neuroses graves e persistentes, psicoses, dependência química e demais casos que necessitam de atendimentos e cuidados intensivos, tornando-se fundamental para o processo de reforma psiquiátrica que substitui as internações em hospitais psiquiátricos.

Uma das práticas que o CAPS oferece são os tratamentos terapêuticos por meio de atividades individuais ou em grupos, tendo como objetivo aproximar os usuários, familiares e comunidade a reintegração ao convívio social. Para que isso possa garantir uma atenção integral aos usuários de álcool e outras drogas, os serviços de saúde devem estar articulados de forma funcional e complementar com os diversos dispositivos da rede.

É realizado com cada indivíduo seu Projeto Terapêutico Singular (PTS), um plano de tratamento elaborado pela equipe de saúde, especialmente para cada paciente, em conjunto com o interessado. Nesse projeto encontram-se as atividades (oficinas, atendimentos) das quais o paciente participará.

Para Campos e Gama (2008), PTS é um dispositivo que tem como objetivo traçar uma estratégia de intervenção para o usuário, levando-se em conta os recursos da equipe, do território, da família e do próprio sujeito.

As perdas causam sofrimento, sendo este um período de desafios, adversidades, dificuldades e que para serem enfrentadas, podem gerar sofrimento mental. São inúmeros os tipos de perda comuns em nossa vida, porém cada um reage de maneira diferente, depende de sua estrutura emocional e 
vivências. O período de pandemia traz uma perda considerável no tratamento, pois não há o contato físico, o "carinho" do toque.

Diante desse momento de pandemia referente à covid-19, infelizmente não podemos realizar grupo terapêutico Álcool e outras Drogas (AD) presencial no CAPS, devido às restrições relativas à aglomeração. Em substituição a esse grupo, foi utilizada, como estratégia, transmissão de vídeo pelo grupo de WhatsApp criado previamente.

As vídeo chamadas em grupo eram realizadas em dias e horários pré-definidos, porém não houve adesão devido a alguns aspectos levantados pelos pacientes, como: 1) dificuldades com as tecnologias empregadas para realização das chamadas remotas; 2) a falta dos recursos básicos necessários para participação nas atividades (celular, computador); 3) prejuízo na privacidade devido ao compartilhamento de espaço reduzido com familiares, e, por vezes, a falta de conhecimento destes sobre a real condição de uso de substâncias psicoativas por parte do paciente; 4) resistência à participação em grupo em modalidade não presencial.

Portanto, está sendo utilizado o recurso de aplicativo de comunicação (WhatsApp) apenas para mensagens de texto e/ou áudio. Assim, os participantes podem interagir no momento em que tiverem disponibilidade e/ ou interesse, podendo o grupo de WhatsApp ser utilizado como recurso para acompanhar o cotidiano dos usuários e ajudá-los em suas necessidades.

Evidencia-se dessa forma a relevância das ferramentas tecnológicas para complemento do cuidado e suporte fornecido aos pacientes, fato constatado por meio de relatos dos participantes. Além de, no momento, ser um recurso substitutivo aos encontros presenciais, legitimando-se como ferramenta para uso complementar mesmo depois da pandemia.

\section{REFERÊNCIAS}

CAMPOS, Rosana Onocko; GAMA, Carlos. Saúde mental na atenção básica. In: CAMPOS, Gaston Wagner de Souza; GUERRERO, André Vinícios Pires (org.). Manual de práticas em atenção básica: saúde ampliada e compartilhada. São Paulo: Hucitec, 2008. 


\section{OBRAS CONSULTADAS}

BRASIL. Ministério da Saúde (MS). Saúde mental no SUS: Os Centros de Atenção Psicossocial. Brasília, DF: Ministério da Saúde, 2014. 